\title{
IN SITU MEASUREMENTS OF ATMOSPHERIC GAMMA RADIATION IN THE GAS FLARING ENVIRONMENT OF THE OLOGBO TOWN, NIGERIA.
}

\author{
Onosohwo, B.U. 1; Mangset, E.W.2 and Khandaker, M.U. ${ }^{* *}$ \\ ${ }^{1}$ Department of Physics, University of Malaya, 50603 Kuala Lumpur, Malaysia. \\ 2 Department of Physics, University of Jos, Plateau State, Nigeria. \\ *Corresponding author. E-mail: mu_khandaker@yahoo.com, Tel.: +60379674099; Fax: +60379674146.
}

\begin{abstract}
ABSTARCT The atmospheric gamma radiation level in gas flaring environment has gained the attention of researchers and environmentalists due to its devastating impact both on the climate and the environment. It is important to make a quantitative assessment of the gamma radiation in the gas flaring environment and nearby residential areas. In situ measurements of the gamma radiation were performed using a nuclear radiation monitoring device: Digilert-50, Stop watch and a geographical positioning system. Data were collected from two different locations: Ologbo town and $40 \mathrm{~m}$ away to the flaring site. Measured data showed that the mean equivalent dose rate at $40 \mathrm{~m}$ away to the flaring site during flaring period was $1.02 \mathrm{mSv} / \mathrm{yr}$, and at Ologbo town was $1.04 \mathrm{mSv} / \mathrm{yr}$. The obtained dose rate in the flaring site and Ologbo town area exceeded the International Atomic Energy Agency and International Commission on Radiological Protection recommended safety limit $(>1 \mathrm{mSv} / \mathrm{yr}$.) for the general public. This shows that the flaring activities have impacted the surrounding environment radiologically. This may pose long-term health side effects on the workers and residents of the host communities. We recommend that flaring should not be done where human population is high or near residential areas because of the radon gas released.
\end{abstract}

(Keyword: Gas flaring, Ologbo town, Atmospheric gamma radiation, In-situ measurements, General public)

\section{INTRODUCTION}

Natural gas is the single phase of petroleum. Global natural gas demand shows rapid increasing trend due to large scale urbanization, specifically in the developing countries. Natural gas, which was once an embarrassing and unwanted by - product or more correctly a co-product of crude-oil production, now provides about one-fifth of all the world's primary energy requirements [1]. Contamination of oil and gas facilities with natural radionuclide is widespread. Both oil and gas are generally contaminated with the ${ }^{238} \mathrm{U}$ and ${ }^{232} \mathrm{Th}$ decay series radionuclides in the rock reservoir. Contamination with radium is common in oil production facilities whereas contamination with radon and radon decay products is prevalent in natural gas production and processing facilities, such as gas wells, pipelines and other gas processing facilities ${ }^{[2]}$. Moreover, the processing of petroleum containing naturally occurring radioactive materials (NORMs) via mechanical, chemical or thermal treatment methods can disrupt radioactive equilibrium due to the separation of different radionuclides into various process streams. Once separated from the primordial parents, the longer-lived radionuclides of the ${ }^{238} \mathrm{U}$ and ${ }^{232} \mathrm{Th}$ series can form their own sub-series, headed by
${ }^{226} \mathrm{Ra}$ and ${ }^{228} \mathrm{Ra}{ }^{[3]}$. Therefore, some contamination may be sufficiently severe; as a result the maintenance and other personnel may be exposed to hazardous concentrations. Radioactive

materials are not necessarily present in a hazardous level in the soil at every well or drilling site. Radioactive wastes from oil and gas drilling take the form of produced water, drilling mud, sludge, slimes or evaporation ponds and pits. It can also concentrate in the mineral scales that form in pipes (pipe scale), storage tanks, or other extraction equipment. Radionuclides in these wastes are primarily ${ }^{226} \mathrm{Ra},{ }^{228} \mathrm{Ra}$ and ${ }^{222} \mathrm{Rn}$. The radon is released to the atmosphere, while the produced water and mud containing radium are placed in ponds or pits for evaporation, re-use or recovery ${ }^{[4]}$. The people most likely to be exposed to this source of radiation are workers at the site. They may inhale radon gas which is released during drilling and produced by the decay of radium. Radon is the largest single contributor to the natural radiation exposure to the general public. Radon is well established human carcinogen for which extensive data are available extending into the range of general population exposure. It is well known that exposure of population to high concentrations of radon and its daughters for a long period lead to pathological effects like the respiratory functional 
changes and the occurrence of lung cancer ${ }^{[5]}$. Two of its radioactive decay products, ${ }^{218} \mathrm{Po}$ and ${ }^{214} \mathrm{Po}$, impact the majority of radiation dose to the lungs rather than the radon itself. Everyone is exposed in daily life to radon, a chemically inert radioactive gas that occurs naturally and is present everywhere [6]. A number of studies have suggested that long term exposure to radon gas may be an important cause of Lung cancer ${ }^{[7]}$. In addition, they are exposed to alpha $(\sim 4.871 \mathrm{MeV})$ and gamma radiation released during the decay of ${ }^{226} \mathrm{Ra}$ and the low energy beta particles $(\sim 0.046 \mathrm{MeV})$ released by the decay of ${ }^{228} \mathrm{Ra}$ (Gamma radiation can also penetrate the skin and cause the risk of cancer) ${ }^{[8]}$.

Only a few earlier studies ${ }^{[9,10,11]}$ were carried out leading to the assessment of radiation doses in the periphery of Nigerian Oil, Gas and Petroleum processing fields. ${ }^{[9]}$ Studied the variation in well head gamma radiation levels at the NPDC oil field in Ologbo, and reported fairly higher values than the normal background level but in agreement with the IAEA's standard on ionizing radiation background level. ${ }^{[10]}$ Assessed gamma - radiation profile of oil and gas facilities in selected flow stations in the Niger - Delta region of Nigeria and reported higher radiation levels at gas facilities than the oil facilities. ${ }^{[11]}$ Studied the gamma - radiation levels in selected oil spilled areas in Rivers State, Nigeria and reported higher equivalent dose rate than the maximum permissible limit recommend by ICRP. However, since there is no study available on the measurement of atmospheric gamma radiation in the gas flaring environment of NPDC flaring site Ologbo, this now laid credence to this study.

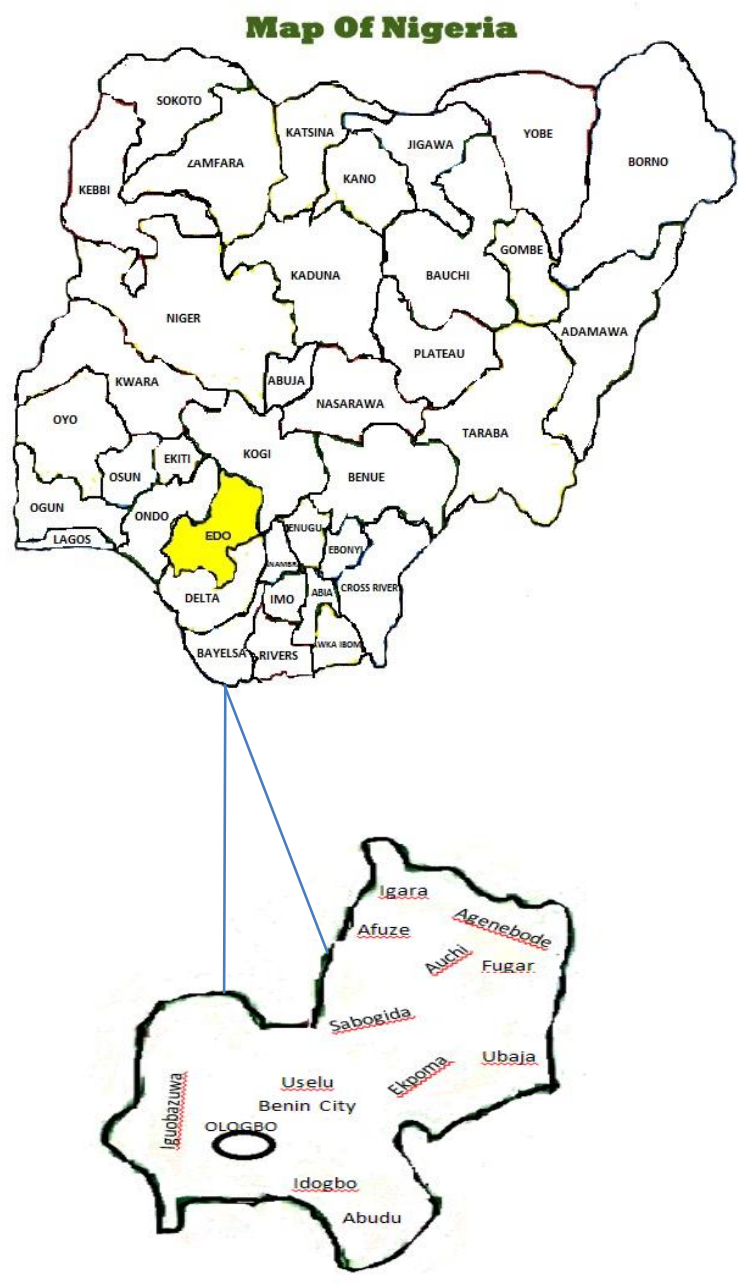

Figure 1. A map of Nigeria showing the study area. 
Moreover, the fear and agitations of workers in this flaring environment and host community in the region on their health safety due to the proximity of the oil facilities to the host community make this research work most timely. Note that, data regarding levels of natural radioactivity and their corresponding radiation doses to the population are still lacking in the studied gas flaring environment. Therefore, the aim of this study is to investigate the potential health hazards posed to workers and the general public in the gas flaring environment of the NPDC oil field in Ologbo. The obtained data will provide essential and additional radiological information for the general population of the host community. The result will also give a baseline data for future detail studies on the atmospheric gamma radiation impacts in a gas flaring environment.

\section{MATERIALS AND METHODS}

\section{Geological settings of the studied area}

Nigeria, one - third larger than Texas and the most populous country in Africa, is situated on the gulf of Guinea in West Africa. Its neighbours are Benin, Niger, Cameroon and Chad. The lower course of the Niger - River flows south through the Gulf of Guinea. Swamps and mangrove forests border the southern coast; inland and hardwood forests ${ }^{[12]}$. The study area is a town/village or other agglomeration of buildings where people live and work in the country of Nigeria. It centre lies at a latitude $6^{\circ} 3$, $8.04^{\prime \prime} \mathrm{N}$ and longitude $5^{\circ} 39^{\prime} 51.25^{\prime \prime} \mathrm{E}$ and it has an elevation of 16 meters above sea level. It is a place with small population in the state of Edo state; Nigeria which is located in the region of Africa. The cities, town and places near Ologbo include Ugbenu, Okuku and Igbobaye. The major occupation of the inhabitants of this area is farming.

\section{Gas flaring situations in Nigeria}

Gas flaring refers to the burning of natural gas that is associated with crude oil when it is pumped up from the ground ${ }^{[13]}$. This associated gas is made up of two elements; carbon and hydrogen and is part of a family of chemical known as hydrocarbons ${ }^{[14]}$. Gas flaring harms the health of the people through emissions that have been linked to cancers, asthma, chronic bronchitis, blood disorders and other diseases ${ }^{[15]}$ especially people living close to a gas flaring site. There is confusion over how much oil and associated gas is produced in Nigeria. The most recent and independent information source suggest that over 3.5 billion standard cubic feet (scf) of associated gas was produced in 2000, of which more than 70\% was flared ${ }^{[16]}$. Between 2012, SPDC installed associated gas gathering (ACG) infrastructure at 37 sites, covering about $66 \%$ of its associated gas production. Unfortunately, 18 of these facilities were either vandalized or not commissioned because of the crises in the Niger Delta between 2006 and 2010. SPDC also claimed that their flaring dropped by about $75 \%$ between 2003 and $2012^{[17]}$.

\section{Data measurements.}

Monitoring of the environmental radiation levels at the flaring station of the NPDC oil field at Ologbo in Edo State, Nigeria was carried out with a well calibrated digilert-50 nuclear radiation monitoring meter (S.E International, Inc. Summer town, USA), which contains a Geiger Muller tube capable of detecting Alpha, Beta, Gamma and X - rays with the temperature range from $-10^{\circ} \mathrm{c}$ to $50^{\circ} \mathrm{c}$ while a geographical positioning system (GPS) was used to measure the precise location of sampling. An in situ approach of background radiation measurement was preferred and adopted to enable sample maintain their original environmental characteristics. The monitor was placed at about $2.0 \mathrm{~m}$ away from the well head and $1.0 \mathrm{~m}$ above the ground. The instantaneous total count was recorded every ten minutes interval while the cumulative count was monitored over a period of about $5-6$ hours daily. Measurements were repeated for two selected days. From the data, the mean counts with time at each location were obtained. The meter usage and readings taken was carried out as reported by ${ }^{[9,18]}$. Readings were obtained between 1100 hours and 1700 hours, since the exposure rate meters have the maximum response to environmental radiation within these hours as recommended by NCRP ${ }^{[19]}$. The count rate per minute recorded in the meter was converted to milli-roentgen per hour $\left(\mathrm{mRh}^{-1}\right)$ using the expression ${ }^{[18]}$.

Count rate per minute $(\mathrm{CMP})=10^{-3}$ roentgen $\times$ Q.F.

Where Q.F. is the quality factor, which is unity for external environment.

The equivalent dose rate was obtained as reported by ${ }^{[19,20]}$ and shows in the Figs. 1 and 2.

$$
1 \mathrm{mRh}^{-1}=((0.96 \times 24 \times 365) / 100) \mathrm{mSvy}^{-1}
$$




\section{RESULTS AND DISSCUSION}

Table I and II shows the results of the in situ measurements in the flaring area and non-flaring area, respectively. The flaring site (40m away) exposure rate ranged from $0.131 \mathrm{mRh}^{-1}$ to $2.910 \mathrm{mRh}^{-1}$ with a mean value of $1.472 \pm 0.832 \mathrm{mRh}^{-1}$. The exposure rate at Ologbo town $(2000 \mathrm{~m})$ ranged from $0.123 \mathrm{mRh}^{-1}$ to $3.057 \mathrm{mRh}^{-1}$ with a mean value of $1.537 \pm 0.868 \mathrm{mRh}^{-1}$. The high value recorded at Ologbo town may be due to the spill of associated crude and the exposure of effluent to the environment. The highest percentage deviation was recorded at the host community (Ologbo), which shows that the resumption of activities in the oil field has impacted the community significantly. Equivalent dose rate is the measure of the amount of radionuclides absorbed by the human body for a given period. ICRP recommended and consequently set the maximum permissible limit was set or non radionuclide industrial worker and the public as $1.0 \mathrm{mSvyr}^{-1}[21]$.

Table 1. Gamma measurement in the Flaring site (40m away) Ologbo

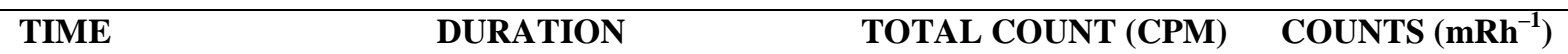

\begin{tabular}{llll}
\hline $13: 00$ & 0 & 0 & 0 \\
\hline $13: 10$ & 10 & 131 & 0.131 \\
\hline $13: 20$ & 20 & 241 & 0.241 \\
\hline $13: 30$ & 30 & 383 & 0.383 \\
\hline $13: 40$ & 40 & 494 & 0.494 \\
\hline $13: 50$ & 50 & 621 & 0.621 \\
\hline $14: 00$ & 60 & 754 & 0.754 \\
\hline $14: 10$ & 70 & 878 & 0.878 \\
\hline $14: 20$ & 80 & 933 & 0.933 \\
\hline $14: 30$ & 90 & 1099 & 1.099 \\
\hline $14: 40$ & 100 & 1215 & 1.215 \\
\hline $14: 50$ & 110 & 1363 & 1.363 \\
\hline $15: 00$ & 120 & 1475 & 1.475 \\
\hline $15: 10$ & 130 & 1600 & 1.600 \\
\hline $15: 20$ & 140 & 1699 & 1.699 \\
\hline $15: 30$ & 150 & 1827 & 1.827 \\
\hline $15: 40$ & 160 & 1969 & 1.969 \\
\hline $15: 50$ & 170 & 2085 & 2.085 \\
\hline $16: 00$ & 180 & 2208 & 2.208 \\
\hline $16: 10$ & 190 & 2325 & 2.325 \\
\hline $16: 20$ & 200 & 2465 & 2.465 \\
\hline $16: 30$ & 210 & 2592 & 2.592 \\
\hline $16: 40$ & 220 & 2711 & 2.711 \\
\hline $16: 50$ & 230 & 2819 & 2.819 \\
\hline $17: 00$ & 240 & 2910 & 2.910 \\
\hline & & &
\end{tabular}

*Average count $\left(\mathrm{mRh}^{-1}\right) \pm \mathrm{SD}=1.472 \pm 0.832$, Where SD is Standard deviation

The mean radiation exposure rate at the flaring site during flaring was slightly lower than where there is no flaring. This is because the combustion product produced during flaring of natural gas will undergo certain recombination and association with the radon gas. This will reduce the radon concentration in the environment, consequently the radiation will decrease. Radon gas which is been liberated from radium decay present in the crude oil/gas products and facilities may be accounted for the variation of 
radiation level within the host community which is also favoured by wind direction and the point of liberation. The flared ionizing radiations (radon gas) into the atmosphere precipitate upon condensing as rain water, thereby constituting radioactive rain water pollution. Unfortunately, this rain water serves as a major source of water for drinking and agriculture in the surveyed area, thereby increasing the radionuclide dose intake by the host community. In addition, a great proportion of the rain water leaks from the oil / gas reservoir and carried to the sub - surface, where it can make contact with sea water. In the sea water, it partially precipitates, while the rest is consumed by the aquatic animals and hence poses a radiological risk to aquatics families and the like ${ }^{[22]}$.

Table 2. Gamma measurement at the Non Flaring site (2000m away) Ologbo town

\begin{tabular}{|c|c|c|c|c|}
\hline TIME & DURATION & $\begin{array}{l}\text { TOTAL } \\
\text { (CPM) }\end{array}$ & COUNT & COUNT $\left(\mathrm{mRh}^{-1}\right)$ \\
\hline 11:00 & 0 & 0 & & 0 \\
\hline $11: 10$ & 10 & 123 & & 0.123 \\
\hline $11: 20$ & 20 & 248 & & 0.248 \\
\hline $11: 30$ & 30 & 386 & & 0.386 \\
\hline $11: 40$ & 40 & 511 & & 0.511 \\
\hline $11: 50$ & 50 & 630 & & 0.630 \\
\hline $12: 00$ & 60 & 787 & & 0.787 \\
\hline $12: 10$ & 70 & 898 & & 0.898 \\
\hline $12: 20$ & 80 & 1029 & & 1.029 \\
\hline $12: 30$ & 90 & 1158 & & 1.158 \\
\hline $12: 40$ & 100 & 1297 & & 1.297 \\
\hline $12: 50$ & 110 & 1423 & & 1.423 \\
\hline 13:00 & 120 & 1546 & & 1.546 \\
\hline $13: 10$ & 130 & 1686 & & 1.686 \\
\hline $13: 20$ & 140 & 1789 & & 1.789 \\
\hline $13: 30$ & 150 & 1922 & & $1: 922$ \\
\hline $13: 40$ & 160 & 2054 & & 2.054 \\
\hline $13: 50$ & 170 & 2184 & & 2.184 \\
\hline $14: 00$ & 180 & 2309 & & 2.309 \\
\hline $14: 10$ & 190 & 2428 & & 2.428 \\
\hline $14: 20$ & 200 & 2554 & & 2.554 \\
\hline $14: 30$ & 210 & 2670 & & 2.670 \\
\hline $14: 40$ & 220 & 2802 & & 2.802 \\
\hline $14: 50$ & 230 & 2944 & & 2.944 \\
\hline $15: 00$ & 240 & 3056 & & 3.056 \\
\hline
\end{tabular}

*Average count $\left(\mathrm{mRh}^{-1}\right) \pm \mathrm{SD}=1.537 \pm 0.868$, Where SD is Standard deviation

Furthermore, the radiation levels recorded for gas flare facilities and natural gas compressor stations are fairly higher than other facilities. This confirms the high concentration of radon gas and heavy metals normally associated with natural and associated gas ${ }^{[9,23]}$. This radon concentration of natural gas at these facilities in the region when compared to those obtained in other countries of the world such as USA, Great Britain and Canada ${ }^{[9]}$, it may be seen that the facilities radiation levels in Nigeria is fairly smaller compared to those reported in USA and Canada where radon concentration (radiation levels) constitutes enormous environmental problems requiring government legislation for the control of NORM contamination in their petroleum industries. 
In this study, it was observed that the mean radiation exposure rate at $40 \mathrm{~m}$ away from the gas flaring site during flaring (figure 2) was a little lower than the mean radiation exposure rate at $2000 \mathrm{~m}$ away from the flaring environment (figure $3)$.

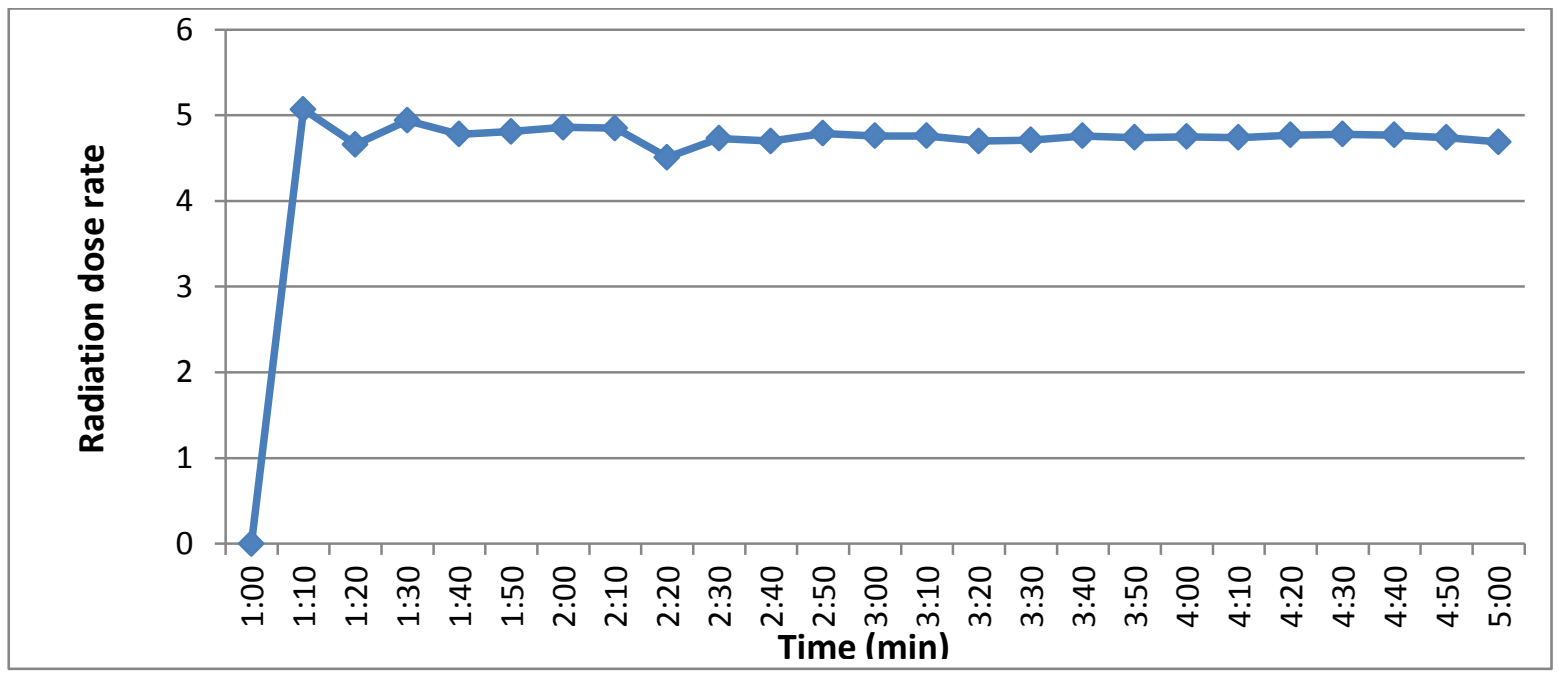

Figure 2. Distribution of radiation dose rate against time at $40 \mathrm{~m}$ away from the flaring site during flaring.

This is because radon concentration varies with geographical location and with soil type of the area ${ }^{[6]}$. From these findings, it was generally observed that the radiation level for the people of Ologbo community was a little high compare to the recommended radiation level of $1 \mathrm{mSv} / \mathrm{yr}$ by the IAEA for the general public. However, there is still the possibility of future health side effects on the site workers and the host community due to long term accumulative dose intake from direct and indirect radionuclides. More so the prevalence of eye carats, lung and bone cancer, leukaemia and mental disorder among host community members and oil and gas facility staff retirees as reported by UNDP and ${ }^{[24,25]}$ is a clear indication of a long term accumulative dose health side effects on workers and host community.

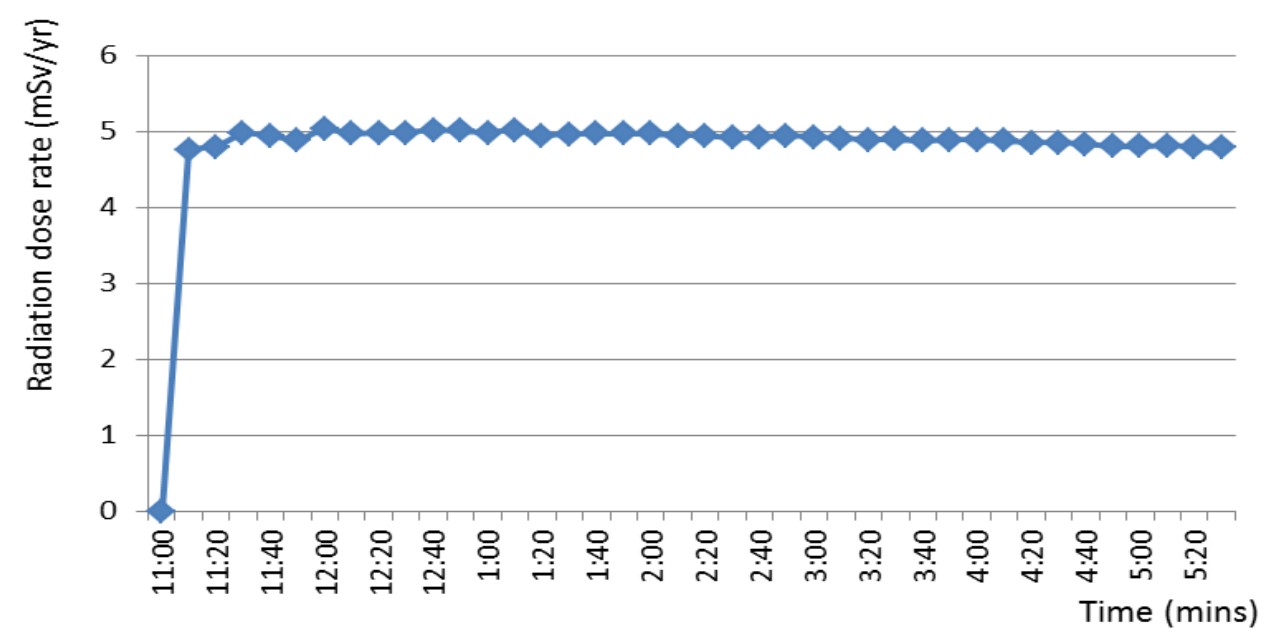

Figure 3. Distribution of radiation dose rate against time at $2000 \mathrm{~m}$ away from the flaring environment. 


\section{CONCLUSION}

The measurement of the atmospheric gamma radiation level at the gas flaring environment of the NPDC oil field in Ologbo, Edo state, Nigeria has been presented and the results has been discussed in detail. The results obtained showed that the soil of the affected area and the residents have been impacted negatively with radioactive elements due to the flaring activities. Since radiation exposure in these environments may constitute serious health hazard on the long term, especially to the flaring site workers and host community, contaminated oil facilities and oil waste materials problems must therefore be adequately recognize and addressed in the oil and gas industries. We therefore recommend that:

- Prompt clean - up exercise should be carried out on any flaring site environment within two days after the operation and long term accumulative effects should be guided.

- Communities within the oil and gas installation areas should have good, cheap and regular access to medical care.

- Communities within 500 meters proximity to flow stations and flare sites should be relocated for the safety of their health.

- All oil and gas installations should meet all known international and ISO standards.

- There should a regular monitoring of radiation levels in these environments.

\section{REFERENCES}

1. Ikoku C.U. (1992). Natural Gas Reservoir Engineering. Krieger Publishing Company, Malabar, Florida, pp. 1.

2. Fennel S.G., Mackin G.M., Madden J.S., McGarry A.T., Duffy J.T., O'colmain M., Colgan P.A. and Pollard D. (2002). Radon in dwellings - The Irish National Radon survey RP II - 02/1, Dublin: Radiological Protection Institute of Ireland.

3. Khandaker M.U., Amin Y.M., Mahat R.H., Nor R.M., Takleef G.H. and Bradley D.A. (2013). The presence of natural radioactivity and $137 \mathrm{Cs}$ in the South China Sea bordering peninsular Malaysia. Radiation Protection Dosimetry 156: 475-480.
4. ICRP (1995). International commission on Radiological Protection. Age - dependent doses to members of the public from intake of Radionuclides - part 5 complication of ingestion and inhalation coefficients, No: 72 (Pergamon Press, Oxford, UK).

5. BEIR VI (1999). Health effects of exposure to radon. Report of the Committee on the Biological effects of Ionizing Radiation. National Research Council. National Academy Press, Washington, DC.

6. UNSCEAR (2006). Effects of ionizing radiation. Report of the United Nations Scientific Committee on the effects of atomic radiation to the General Assembly, with scientific annexes (United Nations, New York, USA) vol. 1.

7. Darby S., Whitley E., Silcocks P., Thakrar B., Green M., Lomas P., Miles J., Reeves G., Fearn T. and Doll R. (1998). Risk of Lung cancer associated with residential radon exposure in south - west England: a case - control study. British Journal of cancer 78: $394-408$.

8. ICRP (1994). Recommendation of the International Commission on Radiological Protection, No: 68 (Pergamon Press, Oxford, UK).

9. Laogun A.A., Ajayi N.O. and Agaja S.A. (2006). Variation in well - head gamma radiation levels at the Nigerian petroleum development company oil field, Ologbo, Edo state, Nigeria. Nigeria Journal of Physics 18: 135 140.

10. Agbalagba E.O., Osakwe R.A. and Olali S.A. (2013). Assessment of gamma radiation profile of oil and gas facilities in selected flow stations in the Niger - Delta region of Nigeria. Journal of Environmental Science and Water Resources 2: $133-139$.

11. Anekwe U.L., Avwiri G.O. and Agbalagba E.O. (2013). Assessment of gamma radiation levels in selected oil spilled areas in Rivers State, Nigeria. Energy science and Technology 5: 33 -37 .

12. www.infoplease.com/country/nigeria.h tml Date of access: 18th of October, 2013. 
13. Nwango V.O., Onyeaba R.A. and Nwachukwu N.C. (2006). Effect of gas flaring on soil microbial spectrum in parts of Niger Delta area of Southern Nigeria. African Journal of Biotechnology 5: $1824-1826$.

14. Igwenagu C.M. (2011). Principle component analysis of global warming with respect to $\mathrm{CO} 2$ emission in Nigeria: an exploratory study. Asian Journal of Mathematics and Statistics 4: $71-80$.

15. Nwaogu L.A. and Onyeze G.O.C. (2010). Environmental Impact of Gas Flaring on Ebocha-Egbema, Niger Delta. Nigerian Journal of Biochemistry and Molecular Biology 25: 25-30.

16. Nwankwo C.N. and Ogagarue D.O. (2011). Effects of gas flaring on surface and ground waters in Delta State Nigeria. Journal of Geology and Mining research 3: $131-136$.

17. SPDC (2013). Gas flaring publication of Shell Petroleum Development Company of Nigeria, April 2013.

18. Avwiri G.O., Agbalagba E.O. and Enyinna P.I. (2007). Terrestrial radiation around oil and gas facilities in Ughelli Nigeria. Asian network for science Information. Journal of Applied Sciences 7: 1543 - 1546.

19. NCRP (1993). National Council on Radiation Protection and Measurements. Limitation of Exposure to Ionizing Radiation: NCRP Report No. 116.

20. Avwiri G.O. and Agbalagba E.O. (2012). Studies on the radiological impact of oil and gas activities in oil mineral lease 30 (OML3) oil fields in Delta State, Nigeria. Journal of Petroleum Environmental Biotechnology 3: 1 -8.

21. ICRP (1999). Recommendations of the International Commission on Radiological Protection, No: 76 (Pergamon Press, Oxford, UK).

22. Stanislav P. and Elema C. (1998). Environmental impact of the off shore oil and gas industries, East Northport, USA.

23. Arogunjo A.M., Ofuga E.E. and Afolabi M.A. (2005). Levels of natural radionuclide in some Nigeria cereals and tubers. Journal of Environmental Radioactivity 82: $1-6$.

24. UNDP (2006). United Nations Development Programme. Niger Delta Human Development Report: Environmental and Social Challenges in the Niger Delta. UN House, Abuja, Nigeria.

25. Otarigho M.D. (2007). Impact of oil spillage on the people of Ughelli South Local Government area, Delta State. Journal of Environmental Research and Policies 2: $44-50$. 